Int. J. Electrochem. Sci., 12 (2017) 10981 - 10993

International Journal of

ELECTROCHEMICAL

SCIENCE

www.electrochemsci.org

\title{
Synthesis and Characterization of Pitch-Coated $\mathrm{Li}_{2} \mathrm{Mn}_{\mathrm{x}} \mathrm{Fe}_{1-\mathrm{x}} \mathrm{SiO}_{4} / \mathrm{C} \mathrm{Composite}$ Cathode Material for Lithium- Ion Batteries
}

\author{
Ho-Ming Cheng ${ }^{1}$,Hong-Gen Dai ${ }^{2}$, Fu-Ming Wang ${ }^{3,4, *}$, Pi-Chuen Tsai ${ }^{2}$ and Wei-Ren Liu ${ }^{5}$ \\ ${ }^{1}$ Department of Materials Science and Engineering, National Taiwan University of Science and \\ Technology, Taipei, Taiwan \\ ${ }^{2}$ Graduate Institute of Material Science and Green Energy Engineering, National Formosa University, \\ Yunlin, Taiwan \\ ${ }^{3}$ Sustainable Energy Center, National Taiwan University of Science and Technology, Taipei, Taiwan, \\ 43, Sec. 4, Keelung Rd., Taipei, 106, Taiwan \\ ${ }^{4}$ Graduate Institute of Applied Science and Technology, National Taiwan University of Science and \\ Technology, Taipei, Taiwan \\ ${ }^{5}$ Department of Chemical Engineering, R\&D Center for Membrane Center, Chung Yuan Christian \\ University, Chungli, Taiwan \\ *E-mail: mccabe@mail.ntust.edu.tw
}

doi: $10.20964 / 2017.11 .06$

Received: 25 June 2017 / Accepted: 21 August 2017 / Published: 12 October 2017

In this study, two cathode materials were synthesized $\left(\mathrm{Li}_{2} \mathrm{Mn}_{0.5} \mathrm{Fe}_{0.5} \mathrm{SiO}_{4}\right.$ and $\left.\mathrm{Li}_{2} \mathrm{Mn}_{0.2} \mathrm{Fe}_{0.8} \mathrm{SiO}_{4}\right)$. The intrinsic characteristics and electrochemical performance of these materials were investigated. These silicate cathode materials have several advantages such as high safety, low cost, low environmental toxicity, and high theoretical energy density. However, they have some drawbacks that must be addressed, including low electronic conductivity and low ionic diffusivity, which limit their practical application in lithium-ion batteries. The $\mathrm{Li}_{2} \mathrm{Mn}_{\mathrm{x}} \mathrm{Fe}_{1-\mathrm{x}} \mathrm{SiO}_{4} / \mathrm{C}$ composite materials were prepared using the sol-gel method. The X-ray diffraction patterns of the synthesized $\mathrm{Li}_{2} \mathrm{Mn}_{\mathrm{x}} \mathrm{Fe}_{1-\mathrm{x}} \mathrm{SiO}_{4} / \mathrm{C}$ composite materials exhibited favorable crystallinity. Pitch was coated on the synthesized composite materials to improve their electronic conductivity. Raman spectroscopy confirmed the high graphitization of the carbon coatings. The discharge capacity of the pitch-coated $\mathrm{Li}_{2} \mathrm{Mn}_{0.2} \mathrm{Fe}_{0.8} \mathrm{SiO}_{4} / \mathrm{C}$ $\left(\mathrm{Li}_{2} \mathrm{Mn}_{0.2} \mathrm{Fe}_{0.8} \mathrm{SiO}_{4} / \mathrm{C} /\right.$ pitch $)$ cathode was $183 \mathrm{mAh} \mathrm{g}^{-1}$ delivered in the first cycle at a rate of $0.1 \mathrm{C}$. The battery cycle retention was $85 \%$ after 30 cycles, demonstrating an excellent cycle life compared with those reported in previous studies. These cathode materials have high potential for application in lithium-ion batteries.

Keywords: lithium ion battery, sol-gel method, orthosilicate cathode, pitch, graphitization 


\section{FULL TEXT}

(C) 2017 The Authors. Published by ESG (www.electrochemsci.org). This article is an open access article distributed under the terms and conditions of the Creative Commons Attribution license (http://creativecommons.org/licenses/by/4.0/). 